\title{
Coronary Artery Spasms and ST-Segment Elevation During Catheter Ablation of Pulmonary Vein Isolation - Cause, Mechanism, and Management -
}

\author{
Takashi Kurita, MD, PhD
}

\section{History of Coronary Artery Spasms (CAS)}

Sixty years have passed since Prinzmetal et al first reported the novel disease concept of a variant form of angina characterized by chest pain occurring at rest (from midnight to early morning or during sleep) and transient ST-segment elevation (STE). ${ }^{1}$ They suggested that the mechanism of the variant form of angina was increased vessel tonus, because it occurred in the absence of an increase in myocardial oxygen demand. Since then, some investigators have succeeded in demonstrating vasoconstriction (total or subtotal obstruction) of an epicardial coronary artery

\section{Article p 264}

during a spontaneous angina attack using coronary angiography (CAG)., ${ }^{2,3}$ In the late 1970s, some groups found that ergonovine can be used for the CAS provocation test, and diagnostic accuracy dramatically improved thereafter., ${ }^{4,5}$

\section{Mechanism of CAS}

As shown in the Figure, CAS can be induced by 2 pathways: (1) hyperreactivity of the coronary artery in response to

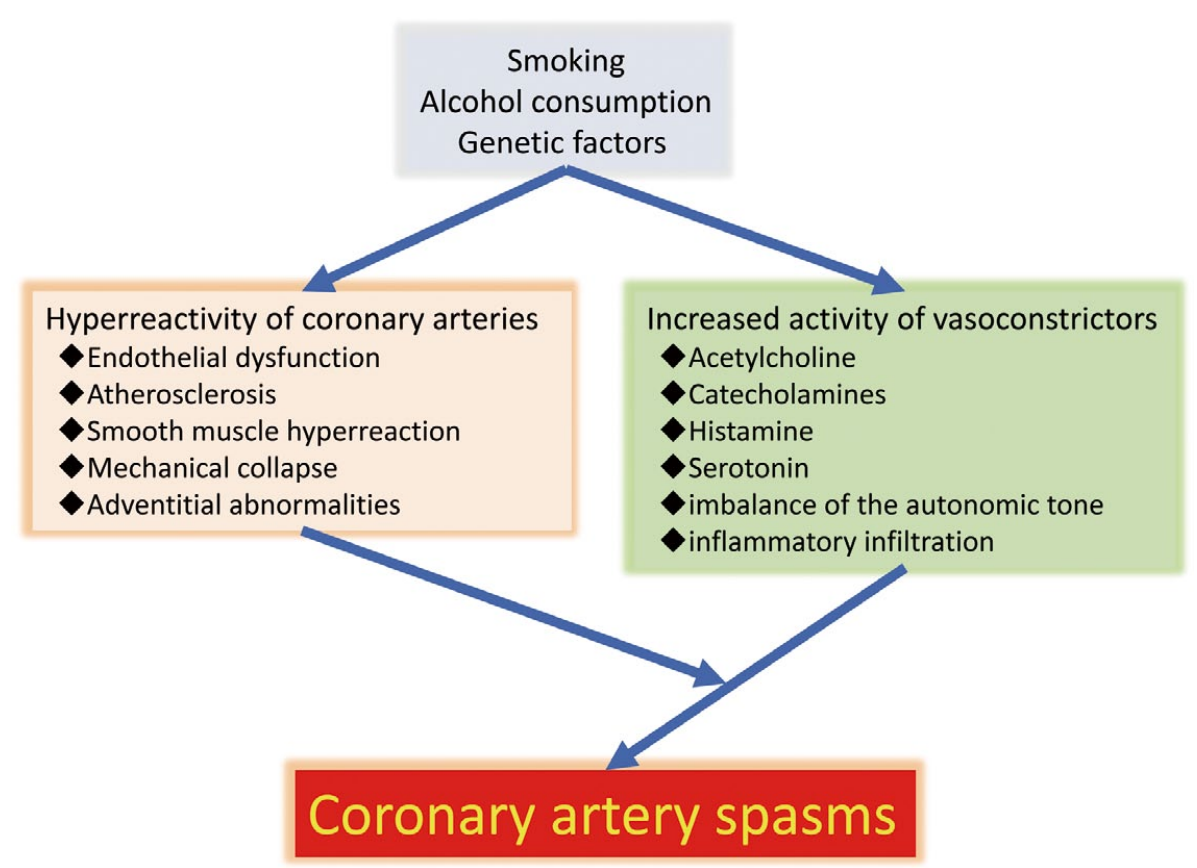

Figure. Mechanism of coronary artery spasm.

The opinions expressed in this article are not necessarily those of the editors or of the Japanese Circulation Society.

Received December 7, 2020; accepted December 7, 2020; J-STAGE Advance Publication released online January 28, 2021

Division of Cardiovascular Center, Kindai University, School of Medicine, Osaka-Sayama, Japan

Mailing address: Takashi Kurita, MD, PhD, Division of Cardiovascular Center, Kindai University, School of Medicine, 377-2

Ohono-Higashi, Osaka-Sayama 589-8511, Japan. E-mail: kuritat@med.kindai.ac.jp

All rights are reserved to the Japanese Circulation Society. For permissions, please e-mail: cj@j-circ.or.jp

ISSN-1346-9843 


\begin{tabular}{|c|c|c|}
\hline & Nakamura et al9 & Tang et $\mathbf{a l}^{8}$ \\
\hline Study design & Retrospective, multicenter & Retrospective, single-center \\
\hline Total no. of patients & 22,232 & 2,965 \\
\hline No. of patients with CAS or STE (\%) & CAS: $42(0.19 \%)$ & STE: $13(0.38 \%)$ \\
\hline Age, years mean $\pm S D$ & $66 \pm 18$ & $57 \pm 8$ \\
\hline Male (\%) & $41 / 42(98 \%)$ & $7 / 13(54 \%)$ \\
\hline AF type: Long-standing/persistent/paroxysmal & $4 / 14 / 24$ & $0 / 1 / 12$ \\
\hline Smoking (\%) & $71 \%$ & ND \\
\hline $\begin{array}{l}\text { STE-related procedure: Sep.P/LAG/energy } \\
\text { delivery }\end{array}$ & $5 / 0 / 21$ & $10 / 3 / 0$ \\
\hline Energy source: RF/Cryo & $8 / 11$ & $13 / 0$ \\
\hline Duration of the STE & ND & $4.6 \mathrm{~min}$ \\
\hline CAG during the STE & $37 / 42$ & $0 / 13$ \\
\hline Documentation of spasms during the STE & $29 / 29$ & $0 / 13$ \\
\hline Culprit artery: RCA/LAD/LCX & $23 / 11 / 0$ & ND \\
\hline STE in the inferior leads (\%) & $79 \%$ & $100 \%$ \\
\hline Incidence of VF or CPA (\%) & $7 / 42(17 \%)$ & $0 / 13(0 \%)$ \\
\hline
\end{tabular}

$\mathrm{AF}$, atrial fibrillation; CAS, coronary artery spasm; CPA, cardiopulmonary arrest; Cryo, cryoablation; LAD, left anterior descending; LCX, left circumflex artery; ND, not described; RCA, right coronary artery; Sep.P, septal puncture; STE, ST-segment elevation; VF, ventricular fibrillation.

vasoconstrictive factors (e.g., endothelial dysfunction, including atherosclerotic plaque, vascular smooth muscle hyperreaction, passive mechanical collapse, and adventitial abnormalities) and (2) increased activity of vasoconstrictive factors (acetylcholine, catecholamines, histamine, serotonin, an imbalance in the autonomic tone, and inflammatory infiltration). ${ }^{6}$ Some clinical situations, such as smoking, alcohol consumption, and genetic factors are very well known as background to promoting CAS. ${ }^{6,7}$

\section{STE During Catheter Ablation}

Tang et al first reported the incidence and characteristics of STE during standard radiofrequency (RF) ablation for circumferential pulmonary vein isolation (PVI) in a large number of patients. ${ }^{\mathbf{8}}$ Their single-center study demonstrated that the STE event rate was $0.39 \%(13 / 2,965)$, and all occurred after transseptal puncture or pulmonary vein venography. Although an air embolism or Bezold-Jarisch like reflex leading to CAS was suggested as the cause of the STE, the obvious etiology of STE was not fully investigated in that study.

In this issue of the Journal, based on their corresponding large-scale multicenter study, Nakamura et al ${ }^{9}$ clearly demonstrate an incidence of CAS related to AF ablation of $0.19 \%(42 / 22,232)$, and CAS was the major cause of STE during PVI ablation. They performed emergency CAG in $88 \%(37 / 47)$ of the patients, and reversible spastic lesions occurred in all (29/29) patients who had continued STE during CAG. However, we should be aware that Nakamura et al only collected subjects with an exact or highly suggestive diagnosis of CAS. ${ }^{9}$ Therefore, from the point of view of "STE" including air embolisms or thromboembolisms, the clinical manifestation of STE may be more frequently observed, as Tang et al described. ${ }^{\mathbf{3}}$ The Table shows a comparison of the results from Nakamura et $\mathrm{al}^{\mathbf{9}}$ and Tang et al. ${ }^{\mathbf{8}}$ In the former study, an autonomic imbalance was highly suggested as the cause of the STE (CAS) because it particularly occurred during cryoablation of the left PVs. Cryoablation is thought to have a strong effect on the epicardial ganglionated plexi, which often exist close to the left PVs. ${ }^{\text {9-11 }}$ In contrast, in the latter study all STE events were unrelated to energy delivery to the PVs but were related to the contrast injection procedure (septal puncture in $10, \mathrm{PV}$ venography in 3 patients). That suggests air embolisms as the major cause of the STE; however, Nakamura et al also described 5 patients who had CAS immediately after septal puncture. ${ }^{9}$ Tang et al considered that the passage of the catheter through the atrial septum, which is innervated profoundly by parasympathetic nerves, might irritate or damage the plexus. ${ }^{8}$ Another possible explanation for the difference between the studies is the energy sources that they used. Tang et al used RF ablation in all patients, whereas Nakamura et al performed cryoablation in $14.7 \%$ of the patients, and showed an approximately 10-fold higher incidence of CAS during cryoablation than RF ablation $(0.33 \%$ vs. $0.04 \%)$.

\section{Risk of CAS (STE) During PVI}

Nakamura et al demonstrated 3 different risk factors for CAS during PVI: male sex, smoking, and a cooled energy source (cryoablation). ${ }^{9}$ However, because they did not collect detailed patient data in those without CAS, the exact estimation of the risk for CAS or VF/CPA in the patients with all 3 conditions is impossible. Therefore, what we should know at the present time is that CAS is rare $(0.2 \%)$ in general but possibly critical $(17 \%$ of CAS, absolute risk of $0.03 \%$ ) during the PVI procedure. Further, physicians are recommended to pay much attention to any ST-segment changes in the inferior ECG leads, especially when they perform PVI using a cryo-balloon catheter in male patients who are current cigarette smokers.

\section{Disclosure}

T.K. received lecture fees from Medtronic Japan.

\section{References}

1. Prinzmetal M, Kennamer R, Merliss R, Wada T, Bor N. Angina pectoris. I: The variant form of angina pectoris. Am J Med 1959; 
27: $375-388$

2. Oliva PB, Pottsm DE, Pluss RG. Coronary arterial spasm in Prinzmetal angina: Documentation by coronary arteriography. N Engl J Med 1973; 288: 745-750.

3. Maseri A, Mimmo R, Chierchia S, Marchesi C, Pesola A, L'Abbate A. Coronary spasm as a cause of acute myocardial ischemia in man. Chest 1975; 68: 625- 633.

4. Heupler FA Jr, Proudfit WL, Razavi M, Shirey EK, Greenstreet $\mathrm{R}$, Sheldon WC. Ergonovine maleate provocative test for coronary arterial spasm. Am J Cardiol 1978; 41: 631-640.

5. Bertrand ME, LaBlanche JM, Tilmant PY, Thieuleux FA, Delforge MR, Carre AG, et al. Frequency of provoked coronary arterial spasm in 1089 consecutive patients undergoing coronary arteriography. Circulation 1982; 65: 1299-1306.

6. Lanza GA, Careri G, Crea F. Mechanisms of coronary artery spasm. Circulation 2011; 124: 1774-1782.

7. Kinlay S. Coronary artery spasm as a cause of angina. Circulation
2014; 129: 1717-1719.

8. Tang RB, Dong JZ, Long DY, Yu RH, Liu XP, Cheng YL, et al. Incidence and clinical characteristics of transient ST-T elevation during transseptal catheterization for atrial fibrillation ablation. Europace 2015; 17: 579-583.

9. Nakamura T, Takami M, Fukuzawa K, Kiuchi K, Kono H, Kobori A, et al. Incidence and characteristics of coronary artery spasms related to atrial fibrillation ablation procedures: Largescale multicenter analysis. Circ J 2021; 85: 264-271.

10. Miyazaki S, Nakamura $\mathrm{H}$, Taniguchi $\mathrm{H}$, Hachiya $\mathrm{H}$, Ichihara N, Takagi T, et al. Impact of the order of the targeted pulmonary vein on the vagal response during second-generation cryoballoon ablation. Heart Rhythm 2016; 13: 1010-1017.

11. Nakagawa H, Scherlag BJ, Patterson E, Ikeda A, Lockwood D, Jackman WM. Pathophysiologic basis of autonomic ganglionated plexus ablation in patients with atrial fibrillation. Heart Rhythm 2009; 6: S26-S34. 